\title{
Nano-Hybrid Thin-Film Composite Carbon Molecular Sieve Membranes
}

\author{
Wojciech Ogieglo ${ }^{\$, *}$, Tiara Puspasari ${ }^{\$}$, Mrinal Kanti Hota ${ }^{\&}$, Nimer Wehbe ${ }^{\%}$, Husam N.
}

\author{
Alshareef ${ }^{\&}$, Ingo Pinnau ${ }^{\$, *}$
}

${ }^{\$}$ Functional Polymer Membranes Group, Advanced Membranes and Porous Materials Center, King Abdullah University of Science and Technology, 23955 Thuwal, Kingdom of Saudi Arabia

\&Materials Science and Engineering, King Abdullah University of Science and Technology, 23955 Thuwal, Kingdom of Saudi Arabia

${ }^{\%}$ Core Lab, King Abdullah University of Science and Technology, 23955 Thuwal, Kingdom of Saudi Arabia

Corresponding authors: wojciech.ogieglo@kaust.edu.sa, ingo.pinnau@kaust.edu.sa

\section{Graphical Abstract}

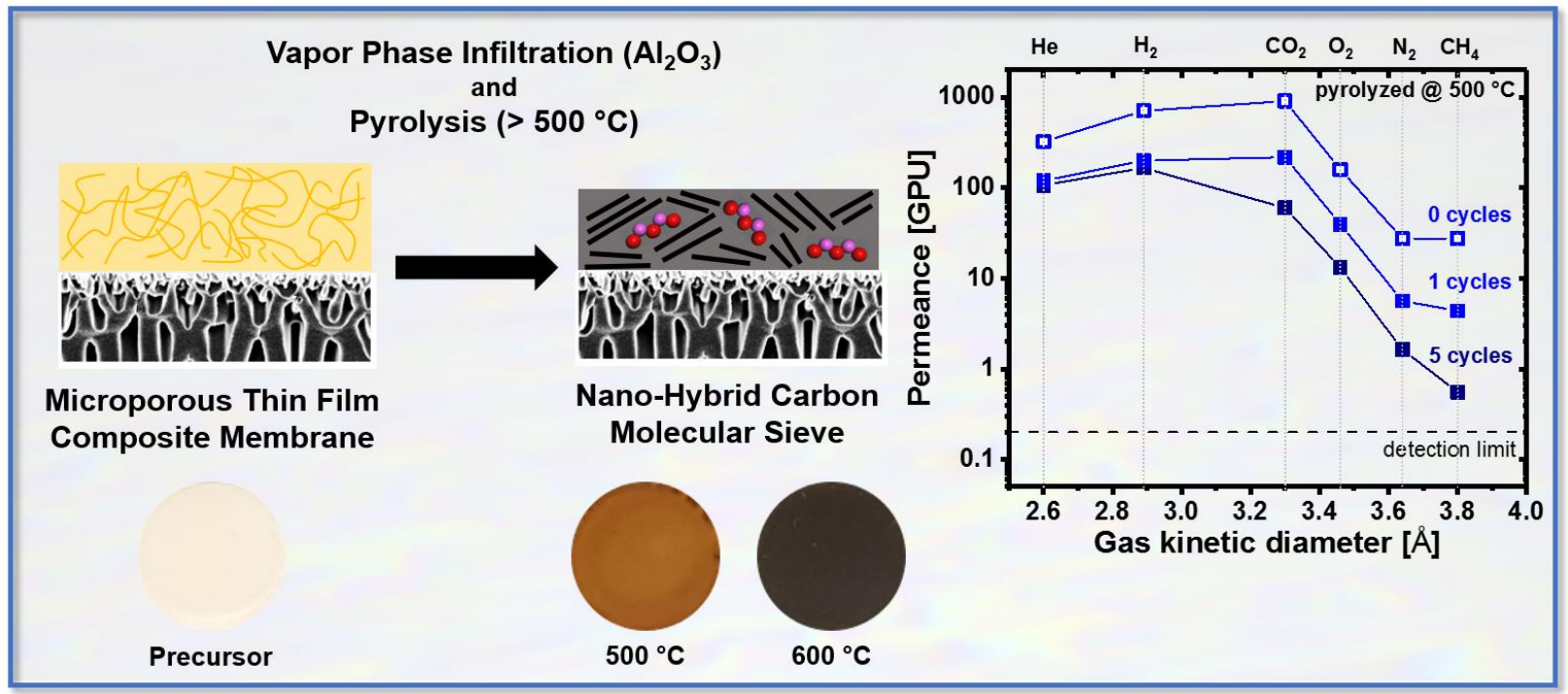

\section{Keywords}

carbon molecular sieves, thin-film composite membranes, gas separation, hybrid materials, nanocomposites, molecular sieving 


\begin{abstract}
Industrial separations belong to some of the most energy-intensive technological processes because of the reliance on heat-consuming unit operations involving a phase change, such as distillation. Membrane technology promises large cuts to those energy needs; however, its progression is hindered as currently available membranes lack separation performance as well as chemical and mechanical stability. To address these challenges, carbon molecular sieves (CMS) have long been suggested as promising candidates providing excellent and robust molecular separation performance. In this work, we introduce nano-hybrid carbon molecular sieve membranes fabricated by pyrolyzing a polyimide of intrinsic microporosity (PIMPI) precursor modified by vapor phase infiltration (VPI). In the VPI process a metal-organic precursor, trimethylaluminum (TMA), first diffuses into the high free volume matrix of the PIM-PI to form a complex with its functional groups. Afterwards, water vapor selectively and locally oxidizes the TMA to form nanodisperesed $\mathrm{Al}_{2} \mathrm{O}_{3}$ within the PIM-PI matrix. Subsequent inert-atmosphere pyrolysis leads to the formation of $\mathrm{Al}_{2} \mathrm{O}_{3}$-doped, high quality, thin-film composite CMS membranes with excellent molecular separation properties for a number of technologically important gas pairs, e.g. $\mathrm{CO}_{2} / \mathrm{CH}_{4}>100, \mathrm{O}_{2} / \mathrm{N}_{2}>9$. The introduction of VPI-doped hybrid CMS membranes allows obtaining extraordinary gas separation performance typical to high temperature un-doped CMS at much lower pyrolysis temperatures. This presents significant advantages such as reduction of mechanical failure risk, wider spectrum of possible supports and reduced fabrication complexity.
\end{abstract}

\title{
Highlights
}

- Introduction of nano-hybrid thin-film composite carbon molecular sieve (CMS) membranes

- Combination of vapor phase infiltration (VPI) and pyrolysis leads to metal oxide doped CMS

- Nano-hybrid CMS membranes show excellent molecular sieving properties

- VPI allows reductions of pyrolysis temperatures by $200-300{ }^{\circ} \mathrm{C}$

- The presented concept enables extremely wide fine-tuning possibilities 


\section{Introduction}

The pressing need to improve industrial energy efficiency is one of the key elements to facilitate the urgent transition of our society towards a more sustainable economy. A very significant part of the total industrial energy consumption is related to separation processes that still largely rely on energy-intensive thermally driven unit operations, such as distillation, drying or evaporation. In this context, membrane technology offers extremely attractive opportunities to reduce those energy demands by up to $90 \%$ [1]. This, however, requires development of not only new membrane materials [2,3] but also design and fabrication of highly productive membrane structures. In particular, design of optimized thin-film composite membranes consisting of a thin, defect-free selective layer can provide high gas permeance (pressure-normalized gas flux) coupled with high gas-pair selectivity while a mechanically robust, low-cost porous support delivers durability and very low resistance to gas transport. These properties allow advanced membranes efficient realization of technologically important separation tasks such as natural gas production, air separation or carbon capture using only pressure difference with virtually no heat input.

Currently available membrane materials, however, are often unable to combine all the necessary characteristics for fabrication of an effective and durable membrane structure. These requirements merely start with attractive intrinsic materials gas separation properties. Ease of thin film fabrication and scale-up, mechanical and chemical resistance, long-term stability, resistance to aging and plasticization (related with swelling induced by condensable gases, e.g. $\mathrm{CO}_{2}$, hydrocarbons etc.) are also extremely important. In this view, carbon molecular sieves (CMS) [4-6] have long been considered as an attractive alternative to both pure polymeric and ceramic membranes. CMS membranes are fabricated by a high temperature (500- 1000 ${ }^{\circ} \mathrm{C}$ ) treatment of a polymer precursor under essentially inert atmosphere and separate gases predominantly based on the diffusivity differences related with the molecular sizes (hence "molecular sieving"). For example, larger gases, such as methane diffuse significantly slower than smaller gases, such as hydrogen or oxygen. As a result of the pyrolytic collapse, a turbostratic, amorphous, and highly microporous (pores $<20 \AA$ ) material is formed. The co-existence of ultramicropores $(<7 \AA)$ together with larger micropores provides exceptionally attractive gas separation properties (usually far above the capabilities of polymeric membrane materials) with very good chemical and plasticization resistance. Simultaneously, the use of an organic polymer precursor contributes to good scalability of CMS membranes by allowing the exploitation of well-established solution coating techniques[7].

Recently, polymers of intrinsic microporosity (PIMs) [3,8,9] which possess high microporosity resulting from a highly frustrated chain packing in a solid state, have been utilized as CMS precursors. This has opened up particularly attractive avenues in energy intensive olefin/paraffin separations [10,11]. 
However, CMS membranes possess several shortcomings, which they partly share with other microporous amorphous materials when fabricated into thin films in the thickness range of a few microns or less. One of the most detrimental ones is physical aging where the excess fractional free volume or microporosity is progressively lost due to a naturally occurring densification of the structure. This process proceeds spontaneously, is accelerated in thin films, and leads to dramatic loss in gas permeability over timescales relevant in membrane processes (weeks to years) [12-15]. Despite its importance, physical aging in thin film CMS membranes has been very rarely reported in the literature [16]. Various efforts have been undertaken to inhibit physical aging, including the polymer design, mixing with fillers, post modification or blending [17-19]. While to some extent effective in thick isotropic films [18], the applicability and effectiveness of those approaches in thin films remain challenging. One of the hurdles more typical to thin film CMS membranes, is the need for cost-effective, mechanically stable supports that would allow tapping into the particularly attractive selectivities of high temperature carbons (pyrolyzed above $700{ }^{\circ} \mathrm{C}$ ). This is usually achieved with relatively expensive porous ceramic supports. Alternatively, polymeric hollow fiber precursors have been utilized which, however, require additional procedures to avoid excessive support pore collapse [20].

Vapor Phase Infiltration (VPI) to create organic-inorganic hybrids has only recently been described to enhance the mechanical properties of spider silk [21]. However, the field is currently undergoing a very rapid development [22-25]. Numerous application areas are expected to benefit from a more widespread use of this relatively novel technique, such as improvement of mechanical properties of common polymers (polyolefins, polystyrene, polyamides, and block copolymers), sorbents, optics, lithography, or electronics etc. Recently, the application of atomic layer deposition (ALD), which is very similar to VPI, for the modification of membrane properties has been reviewed by Yang et al. [26]. Those approaches, however, mostly relied on surface (top interface or inner pore surface) modifications. In their recent work, McGuinnes et al. have used VPI to improve stability of PIM-1 membranes for organic solvent applications [27] demonstrating that upon extensive doping and inorganic network formation demanding emerging applications could be addressed. In addition, only one more report exists on attempting to fabricate ceramic porous membranes with much larger pores $(\sim 10 \mathrm{~nm})$ by using infiltrated block copolymers as templates [28]. To date, however, VPI has not been utilized in microporous membranes in conjunction with pyrolysis to produce metal oxide-doped CMS membranes.

In this work, we present a new method to fabricate nano-hybrid CMS thin-film composite membranes with microporosity fine-tuned on a molecular level by a dispersion of inorganic $\mathrm{Al}_{2} \mathrm{O}_{3}$ within the carbon matrix. The membranes were fabricated by vapor phase infiltration (VPI) of the thin-film PIM-PI precursor with a metal-organic, Al-containing compound (trimethylaluminum, TMA) followed by oxidation with water 
vapor and, eventually, pyrolysis. The resulting nano-hybrid CMS membranes show excellent separation properties, typical to high-temperature carbons, yet achieved at moderate pyrolysis temperatures. This strategy could potentially simplify the choice of a suitable CMS membrane support for practical applications. Moreover, the physical aging characteristics of the obtained membranes are distinct from the typical fast loss of permeance with largely preserved selectivity typical to un-doped CMS thin films. The VPI-derived nano-hybrid CMS membranes, in contrast, seem to gain selectivity with aging up to 2 months after fabrication. Given a very large spectrum of available metal-organic VPI precursors, as well as broad possibilities to optimize the doping process we believe that the presented method shows a tremendous potential both for a precise fine-tuning of the CMS membrane properties and for scale-up.

\section{Experimental part}

\section{Membrane fabrication}

The CMS precursor, polyimide of intrinsic microporosity (PIM-PI) SBFDA-DMN, was synthesized by polymerization of a spirobifluorene-based dianhydride with 3,3'-dimethylnaphtihidine, as described earlier [29]. The polymer possessed a molecular weight $M_{\mathrm{n}}=6.5 \times 10^{4} \mathrm{~g} \mathrm{~mol}^{-1}$ with a polydispersity index (PDI) of 1.92 and an internal surface area $S_{\mathrm{BET}}=686 \mathrm{~m}^{2} \mathrm{~g}^{-1}$. The decomposition onset was determined by TGA at $\sim 520^{\circ} \mathrm{C}$. The polymer combined a PIM character (high internal surface area and a rigid backbone) with a very high aromatic carbon content (84 wt.\%) which was transformed into high quality carbon molecular sieve membranes following pyrolysis [30].

Thin-film composite membranes were fabricated by deposition of $50 \mu \mathrm{L}$ of $\sim 1$ wt.\% SBFDA-DMN solution in chloroform on top of anodized aluminum substrates (Whatman Anodisc ${ }^{\mathrm{TM}}$, Sigma Aldrich) with $20 \mathrm{~nm}$ surface pores. This resulted in a 1-1.5 micron layer thickness as measured with spectroscopic ellipsometry on five spots on the surface. The sufficiently small surface pores assured virtually no pore intrusion by the coating solution and resulted in a sharp, well-defined support/thin-film interface (Figure S1). For the XPS, SIMS, spectroscopic ellipsometry, AFM and optical imaging an additional set of samples were fabricated by spin-coating $\sim 3 \mathrm{wt}$.\% polymer precursor solution on top of silicon wafers with $500 \mathrm{~nm}$ thermally grown silicon oxide. The resulting SBFDA-DMN films were about $300 \mathrm{~nm}$ thick. No additional treatment of either PIM-PI membranes or thin films was applied prior to VPI modification.

\section{Membrane modification by Vapor Phase Infiltration (VPI)}

A commercial atomic layer deposition system (Cambridge Nanotech, model Savannah S100) was used to perform the vapor phase infiltration (VPI) of the precursor polymer by using trimethylaluminum (TMA) as VPI precursor followed by subsequent oxidation with deionized water (vapor). The deposition was carried out at $200{ }^{\circ} \mathrm{C}$ with a constant $\mathrm{N}_{2}$ flow of $15 \mathrm{sccm}$ at 0.2 Torr pressure. The infiltration was accomplished 
by isolating the ALD chamber from the pumping line and pulsing the precursor or water (15 ms pulse duration) followed by $10 \mathrm{~s}$ exposure before purging the chamber again. Exposure to TMA with a subsequent exposure to water vapor constituted one cycle. In this work, 1, 5 and 20 cycles were used to modify the polymer precursor. Control samples (0 cycles) underwent exactly the same heating protocol as VPImodified samples without, however, exposure to either of the reactants.

\section{Membrane characterization}

Multiple characterization techniques were used to extensively characterize the fabricated hybrid samples. X-Ray photoelectron spectroscopy (XPS) analysis was performed on a Kratos Axis Ultra DLD instrument equipped with a monochromatic $\mathrm{Al} \mathrm{K} \alpha$ X-ray source $(\mathrm{h} v=1486.6 \mathrm{eV})$ operated at $120 \mathrm{~W}$ under UHV conditions ( $\left.\sim 10^{-9} \mathrm{mbar}\right)$. The spectra were recorded in a hybrid mode using electrostatic and magnetic lenses and an aperture slot of 300 by $700 \mu \mathrm{m}$. The survey and high-resolution spectra were acquired at fixed analyzer pass energies of $160 \mathrm{eV}$ and $20 \mathrm{eV}$, respectively. The samples were mounted in a floating mode to avoid differential charging. The spectra were acquired under charge neutralization conditions.

Atomic force microscopy (AFM) was performed using a TESPA probe in a tapping mode with the Dimension ICON instrument. Areas of $1 \mu \mathrm{m}^{2}$ were analyzed on all pristine, hybrid and pyrolyzed samples on Si wafer-deposited films. The optical microscope of the AFM device was used to take optical images of all samples under identical illumination conditions.

Dynamic secondary ion mass spectrometry (SIMS) was done using a Hiden instrument (Warrington, UK) operated under ultra-high vacuum conditions (typically $10^{-9}$ Torr). A continuous $\mathrm{Ar}^{+}$beam was employed at $4 \mathrm{keV}$ to sputter the sample surface while the selected ions were sequentially collected using a MAXIM spectrometer equipped with a quadrupole analyzer. The raster of the sputtered area was approximately 750 $\mathrm{x} 750 \mu \mathrm{m}$. To avoid the edge effect during depth profiling data were recorded from a small area located in the middle of the eroded region. The acquisition area was adjusted using adequate electronic gating to about $75 \times 75 \mu \mathrm{m}$. A conversion of the sputtering time to sputtering depth was carried out assuming a constant sputtering rate and accounting for the measurement of the crater depth with a stylus profiler from Veeco.

Spectroscopic ellipsometry (SE) was used to determine the thickness of the precursor membranes deposited on the alumina substrates, as well as the thickness and optical properties of the Si wafer deposited samples. This approach has been previously demonstrated for studies on similar composite membrane systems [3032]. SE was conducted using M-2000 DI instrument from J. A. Woollam Co. equipped with focusing optics (300 $\mu \mathrm{m}$ short axis) in a wavelength range $192-1700 \mathrm{~nm}$ at five angles of incidence $(55,60,65,70$ and $75^{\circ}$ ). The analysis was performed as previously reported [30] and involved utilization of either the Cauchy model in a range of $500-1700 \mathrm{~nm}$ (with included Urbach tail to handle the light absorption) or B-Spline 
model [33] in a full spectral range. Effective medium approximation theory [34] (EMA) was used to extract the volume fractions of $\mathrm{Al}_{2} \mathrm{O}_{3}$ within the polymer film by assuming molecular level inclusion of the inorganic domains into the organic polymer thereby satisfying the EMA requirements. The pristine polymer dielectric function was first fitted using the B-Spline to serve as the first component in the EMA mixture. The optical properties of the second component, $\mathrm{Al}_{2} \mathrm{O}_{3}$, were taken from a literature database [35]. A 15layer graded optical dispersion was used to approximate the distribution of the $\mathrm{Al}_{2} \mathrm{O}_{3}$ within the interface of the hybrid films.

Gas permeances, expressed in 'gas permeation units', with 1 GPU $=1 \times 10^{-6} \mathrm{~cm}^{3}(\mathrm{STP}) \mathrm{cm}^{-2} \mathrm{~s}^{-1} \mathrm{cmHg}^{-1}$ or $3.35 \times 10^{-10} \mathrm{~mol} \mathrm{~m}^{-2} \mathrm{~s}^{-1} \mathrm{~Pa}^{-1}$, were measured at $21 \pm 1^{\circ} \mathrm{C}$ by the constant pressure/variable volume method (utilizing bubble flow meter) using the previously reported protocol [30]. In brief, following VPI and pyrolysis the membranes were placed in stainless steel high pressure $47 \mathrm{~mm}$ diameter permeation cells (Milipore) with appropriate ring-shaped masks and rubber o-rings. Active membrane area was $0.65 \mathrm{~cm}^{2}$. Maximum pressure for each single gas test was 8 bar with the exception of $\mathrm{CO}_{2}$ for which 4 bar was used to limit plasticization effects. After stabilization of gas flow (which occurred within 2 hours) the cells were thoroughly purged before proceeding to the next gas. Ideal gas selectivities $\left(\alpha_{\mathrm{ij} j}\right)$ were calculated by dividing permeances of $i$ an $j$ gases, respectively. Prior to gas separation performance testing all membrane samples were coated by a protective thin layer of polydimethylsiloxane, PMDS (500 - $1000 \mathrm{~nm})$. The PDMS coating is commonly employed both in academic research as well as in industry to help eliminate the detrimental influence of occasional pinhole membrane defects. The presence of a highly permeable PDMS layer had a negligible effect on the intrinsic CMS thin film performance as thoroughly evaluated earlier [30].

\section{Results and discussion}

Figure 1a shows the scheme of the VPI process applied directly to the thin (CMS) PIM-PI precursor film followed by inert atmosphere pyrolysis to form the carbon molecular sieve and final protective thin film PDMS deposition. The VPI process itself can be repeated multiple times thereby allowing for precise tuning of the resulting aluminum oxide volume fraction (as determined by spectroscopic ellipsometry and XPS, Supporting Information). Trimethylaluminum (TMA), present in the vapor phase as a dimer, is suggested to form a reversible complex with the functional groups of the polymer matrix [36] (imide groups in the case of our PIM-PI), Figure 1b. Subsequent oxidation with water vapor results in aluminum oxide formation loosely bound with the polymer matrix, however no exact mechanism for this process is known $[23,27]$. Simultaneously, the high microporosity of the PIM-PI facilitates efficient diffusion of TMA deep into the selective polymer layer. These large penetration depths for short exposure times are uncommon in conventional low-free- volume polymers (e.g. polyolefins or polyamides) where, in contrast, a thin dense layer of $\mathrm{Al}_{2} \mathrm{O}_{3}$ tends to form at the top interface (at least at comparatively high deposition temperatures to 
assure fast oxidation kinetics) [37]. Larger penetration depths (several microns) in those conventional polymers would require significant increase in the exposure time or changes of process conditions, in particular temperature [38]. The significant penetration depth is confirmed by the secondary ion mass spectrometry data, Figure 2a, where in the case of infiltrated samples the Al-ion signal persists up to depths of about 150-200 $\mathrm{nm}$. Additionally, the Al-ion signal shows almost no variation upon subsequent high temperature $\left(500\right.$ and $600{ }^{\circ} \mathrm{C}$ ) pyrolysis. The easy tunability of the $\mathrm{Al}_{2} \mathrm{O}_{3}$ volume fraction is demonstrated in additional SIMS diagrams (Figure S2) where its intensity increases with increasing number of VPI cycles. Optical images of the pristine polymer samples, as well as the pyrolyzed and non-pyrolyzed hybrids showed no changes to the top film surface (Figure S3). AFM confirmed a very low surface roughness (RMS $<0.5 \mathrm{~nm}$ ) with a slight increase for the hybrid sample pyrolyzed at $500{ }^{\circ} \mathrm{C}$ (Figure S4).
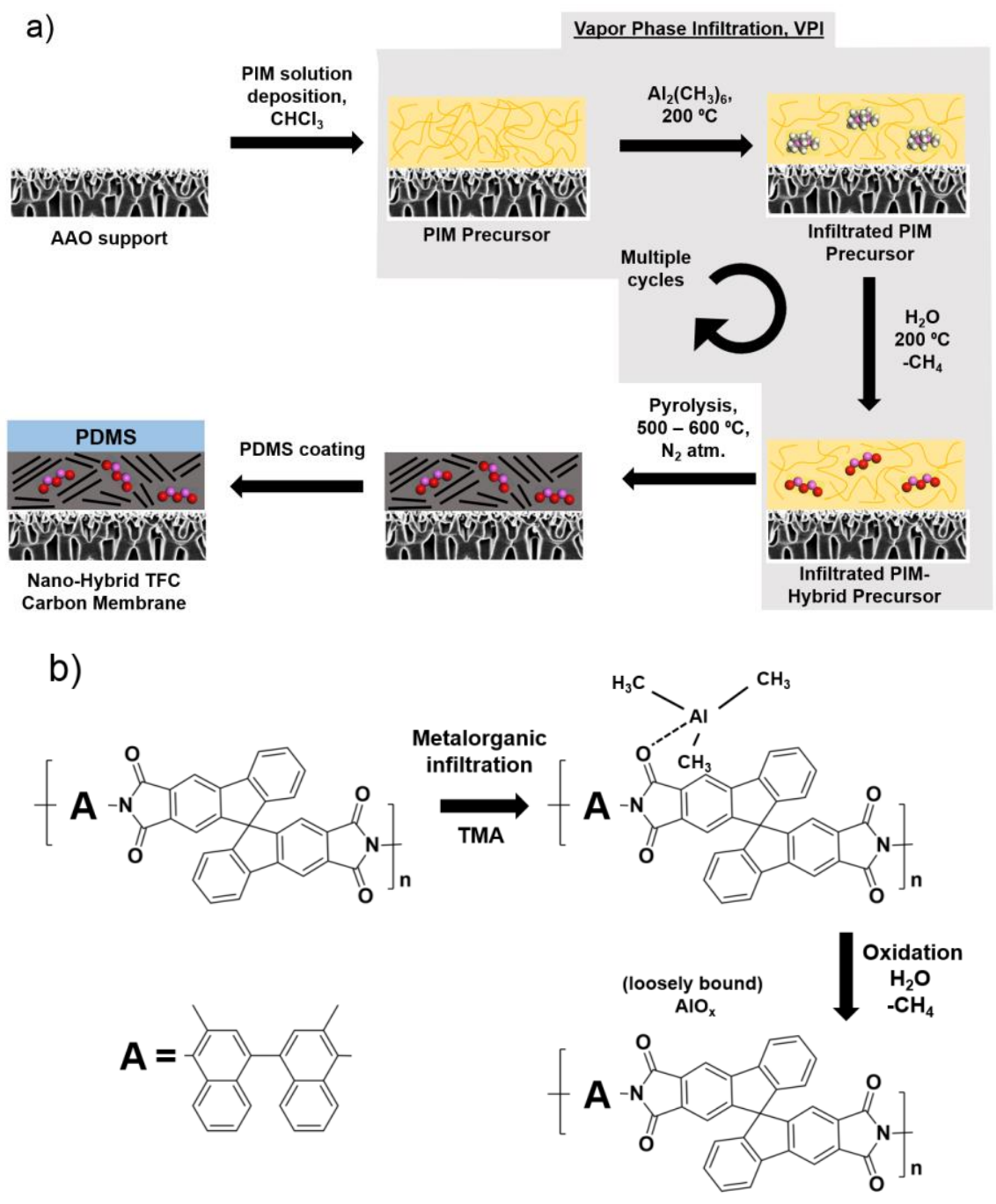

$$
2 \mathrm{Al}\left(\mathrm{CH}_{3}\right)_{3}+3 \mathrm{H}_{2} \mathrm{O} \rightarrow \mathrm{Al}_{2} \mathrm{O}_{3}+6 \mathrm{CH}_{4}
$$


Figure 1. a) Scheme of the thin-film composite carbon membrane fabrication process based on a PIM-polymide with incorporated vapor phase infiltration step, which can be repeated multiple times prior to pyrolysis, and application of the protective PDMS coating; b) proposed chemical scheme showing the creation of the organic-inorganic complex around the imide functional group of the pristine polymer followed by an oxidation reaction leading to a nanodispersed $\mathrm{Al}_{2} \mathrm{O}_{3}$ within the PIM matrix.

XPS data, presented in Figure 2b and Table S1, strongly suggests that Al is efficiently incorporated at a molar fraction of about $7.7 \%$ after just 5 VPI cycles and remains in the structure following the pyrolysis. The peak shape analysis for $\mathrm{Al} 2 \mathrm{p}$ peaks, Figure $\mathbf{2 b}$, indicates that $\mathrm{Al}$ exists within the structure predominantly as aluminum oxide (a shift from $72.6 \mathrm{eV}$ for oxidation state of 0 to around $74.6 \mathrm{eV}$ in $\mathrm{Al}_{2} \mathrm{O}_{3}$ ) and thus presumably remains rather loosely (physically) bound to the polymer chains. This observation is in agreement with extensive previous studies and seems to be a general feature of the VPI process in most typical cases e.g. deposition of $\mathrm{Al}_{2} \mathrm{O}_{3}, \mathrm{ZnO}$ or $\mathrm{TiO}_{2}$ [23]. With respect to $\mathrm{O} 1 \mathrm{~s}$ peak, the control samples $(0$ cycles) show a rather symmetrical peak shape centered at around $532.3 \mathrm{eV}$, which can be ascribed to the carbonyl groups of the pristine polymer. For the Al incorporated samples (both before and after pyrolysis), the $\mathrm{O} 1 \mathrm{~s}$ peak is broadened due to an additional contribution shifted toward lower binding energy, which can be assigned to formation of $\mathrm{Al}$ oxide bonds. Clearly, $\mathrm{Al}_{2} \mathrm{O}_{3}$ remains within the structure following pyrolysis. 
a)
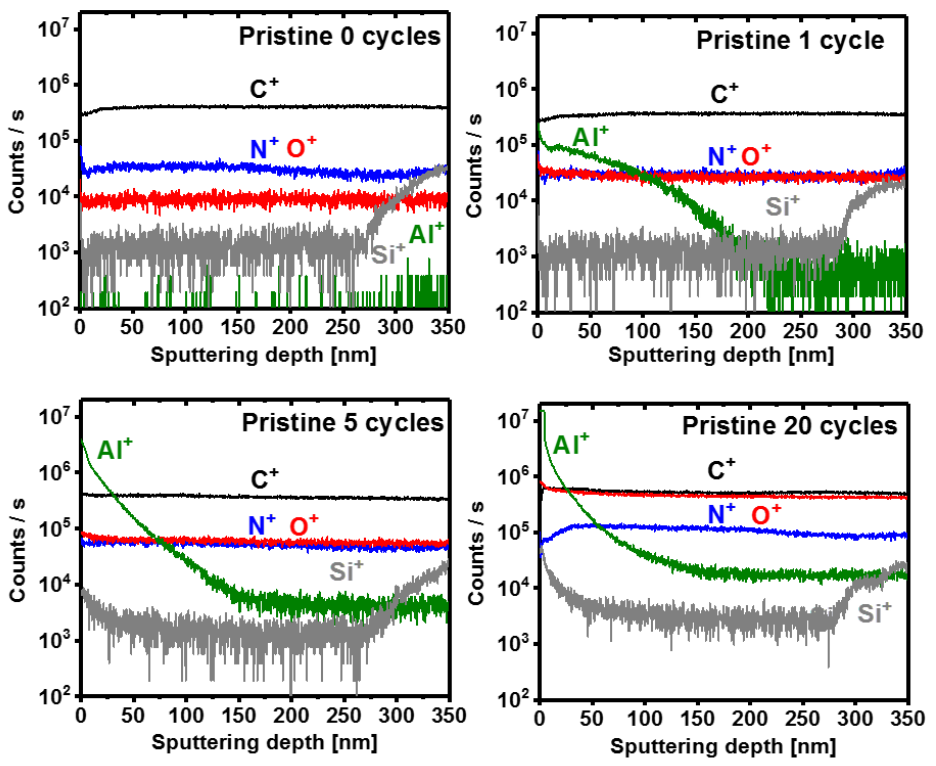

b)

X-Ray Photoelectron Spectroscopy
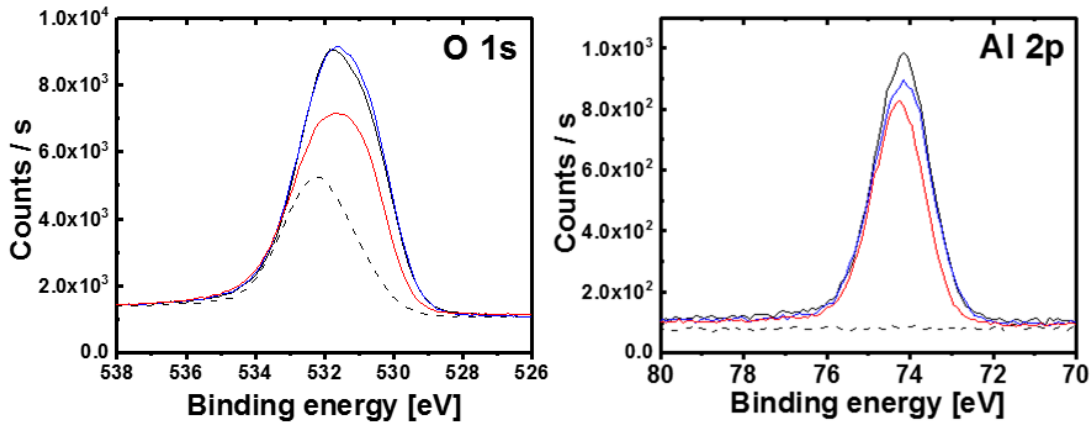

Figure 2. a) Secondary ion mass spectrometry (SIMS) data showing a graded infiltration of Al from the surface up to about 150-200 nm depth into the $250-300 \mathrm{~nm}$ PIM precursor film; the $\mathrm{Al}$ ion deposition is preserved upon high temperature treatment (pyrolysis); additional SIMS data are shown in the Supporting Information. b) X-Ray photoelectron spectroscopy data for $\mathrm{O} 1 \mathrm{~s}$ and $\mathrm{Al} 2 \mathrm{p}$ peaks, indicating that $\mathrm{Al}_{2} \mathrm{O}_{3}$ is chemically intact and loosely (physically) bound within the PIM precursor as well as after the pyrolysis.

Following VPI and pyrolysis, the alumina-supported nano-hybrid CMS membranes were tested with respect to their ideal gas separation performance. In Figure 3, data for freshly made samples (aged for 1 day) are presented. Remarkably, the VPI resulted in strong enhancement of the molecular sieving character of the pyrolyzed membranes, Figure 3. The unmodified CMS membranes (denoted as " 0 cycles") showed some solubility contribution of the more condensable $\mathrm{CO}_{2}$ (as expected from the solution-diffusion mechanism [39]) and, therefore, permeated faster than the significantly smaller $\mathrm{He}$ and $\mathrm{H}_{2}$. After just one VPI cycle the character started to change and by five VPI cycles the membranes displayed very strong 
molecular sieving with the permeances closely following the molecular size of the gas molecules. Simultaneously, permeances of all gases reduced significantly. In particular, for the five VPI cycles sample pyrolyzed at $600^{\circ} \mathrm{C}$ a very strong sieving effect was revealed by a drastically reduced (to below detection limit) permeance of methane, the largest gas in our test series. The changes in the gas separation performance of the hybrid CMS membranes indirectly indicate that introduction of molecularly dispersed $\mathrm{Al}_{2} \mathrm{O}_{3}$ appeared to tighten the ultramicropores and reduce the overall porosity. These effects are similar to those that occur in bulk CMS membranes upon increase of pyrolysis temperatures [40]. However, a direct characterization of porosity and pore size distribution in $\sim 1$ micron films remains extremely challenging because of a lack of suitable experimental techniques.
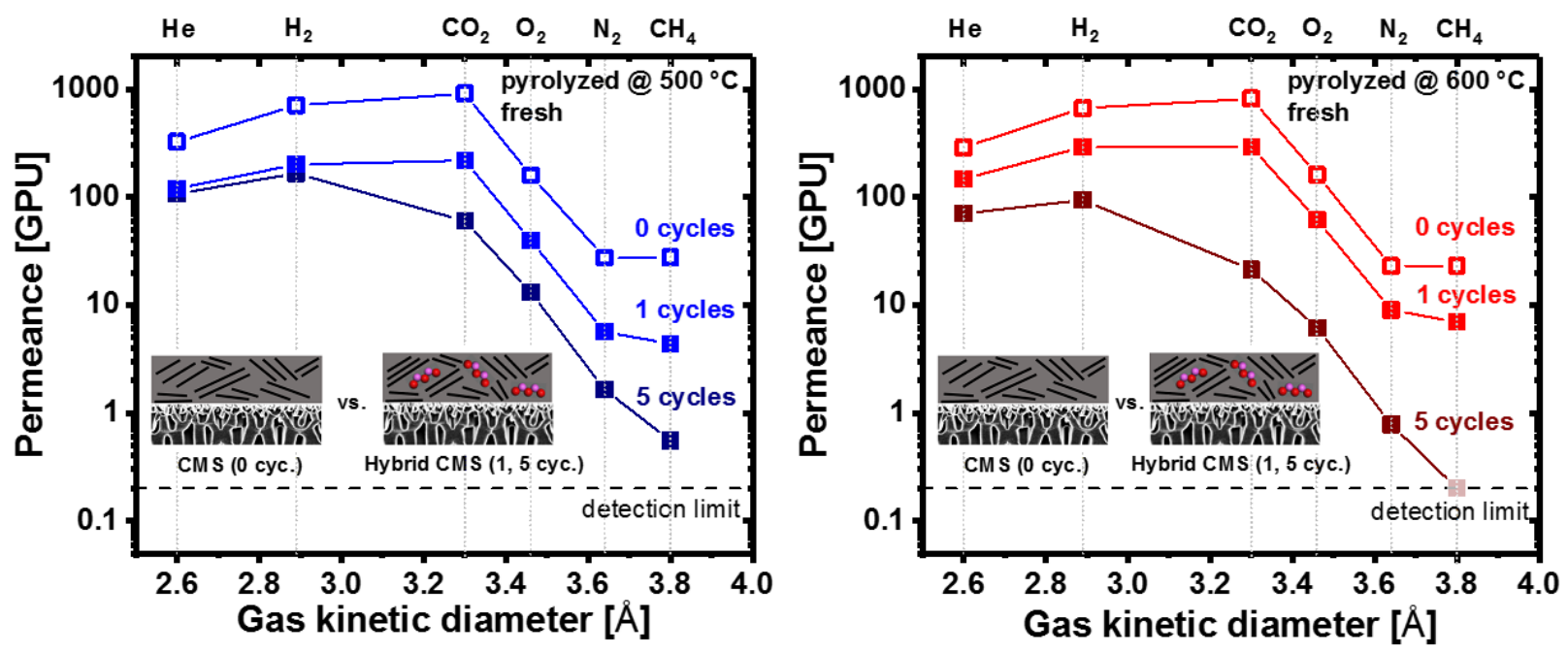

Figure 3. Membrane permeances as a function of the kinetic gas diameters showing an increasing molecular sieving ability with increasing number of vapor infiltration cycles for samples pyrolyzed at 500 and $600{ }^{\circ} \mathrm{C}$.

Table 1 displays the performance data for the freshly prepared (1 day aged) nano-hybrid CMS membranes prepared in this work, nano-hybrids aged for 60 days (500 and $600{ }^{\circ} \mathrm{C} 1 \mathrm{VPI}$ cycle each), as well as data for undoped analogical samples pyrolyzed between 500 and $800{ }^{\circ} \mathrm{C}$ from our previous study [30]. We note here, that Raman spectra of the undoped samples pyrolyzed at 500 and $600{ }^{\circ} \mathrm{C}$, Figure S9, indicate that at $500{ }^{\circ} \mathrm{C}$ the CMS structure does not yet fully form (this is the transition carbon region with partly degraded polymer precursor) while at $600{ }^{\circ} \mathrm{C}$ the $\mathrm{D}$ and $\mathrm{G}$ peaks typical to the amorphous turbostratic carbon structure do appear. All VPI-modified membranes showed excellent separation performance combining high gaspair selectivities with high permeances. Increasing the number of VPI cycles strongly correlated with enhancement in gas-pair selectivity, for instance membranes pyrolyzed at $600{ }^{\circ} \mathrm{C}$ exhibited $\mathrm{CO}_{2} / \mathrm{CH}_{4}$ selectivity of 35.3, 41.9 and 106 by applying 0,1 and 5 VPI cycles, respectively. The VPI process followed by pyrolysis at $500-600{ }^{\circ} \mathrm{C}$ enables shifting the molecular sieving properties of the hybrids close to that of 
undoped CMS membranes prepared at $200-300{ }^{\circ} \mathrm{C}$ higher pyrolysis temperatures. This remarkable finding suggests that the introduction of the molecularly dispersed $\mathrm{Al}_{2} \mathrm{O}_{3}$ is able to tighten the microporosity essentially mimicking the very strong sieving capabilities of extremely dense, high-temperature CMS membranes without the need for extremely high treatment temperatures. This feature may present very significant practical advantages by extending the spectrum of available less heat resistant porous supports for preparation of CMS membranes. In addition, the risk of mechanical damage because of the thermal stress, like pore collapse in all-polymer fibers or cracking, could be greatly reduced. Lastly, avoiding very high pyrolysis temperatures may have obvious practical implications in terms of membrane fabrication complexity and cost.

Table 1. Permeances and Ideal Selectivities of Freshly Fabricated (1 day aged) Nano-Hybrid and Control (Un-doped) Carbon Molecular Sieve Membranes.

\begin{tabular}{|c|c|c|c|c|c|c|c|c|c|}
\hline \multirow[b]{2}{*}{ Membrane } & \multicolumn{6}{|c|}{ Permeance [GPU] } & \multicolumn{3}{|c|}{ Ideal Selectivity, $\alpha[-]$} \\
\hline & He & $\mathbf{H}_{2}$ & $\mathbf{N}_{2}$ & $\mathbf{O}_{2}$ & $\mathrm{CH}_{4}$ & $\mathrm{CO}_{2}$ & $\mathrm{O}_{2} / \mathrm{N}_{2}$ & $\mathrm{CO}_{2} / \mathrm{CH}_{4}$ & $\mathrm{H}_{2} / \mathrm{N}_{2}$ \\
\hline Pristine 0 cycles & 420 & 1127 & 120 & 396 & 168 & 1948 & 3.3 & 11.6 & 9.4 \\
\hline Pristine 5 cycles & 378 & 882 & 104 & 303 & 133 & 1461 & 2.9 & 11.0 & 8.5 \\
\hline $500{ }^{\circ} \mathrm{C} 0$ cycles & 324 & 707 & 27.4 & 159 & 27.6 & 907 & 5.7 & 30.3 & 25.8 \\
\hline $600{ }^{\circ} \mathrm{C} 0$ cycle & 288 & 665 & 22.9 & 161 & 23.1 & 813 & 7.0 & 35.3 & 28.9 \\
\hline $700^{\circ} \mathrm{C} 0$ cycle & 70 & 196 & 6.4 & 38.7 & 4.3 & 228 & 6.1 & 53.0 & 30.8 \\
\hline $800^{\circ} \mathrm{C} 0$ cycle & 96.2 & 178 & 1.1 & 12.9 & 0.47 & 58.3 & 11.5 & 124 & 159 \\
\hline $500^{\circ} \mathrm{C} 1$ cycle & 146 & 271 & 13.0 & 65.8 & 15.0 & 356 & 5.1 & 23.8 & 20.9 \\
\hline $600^{\circ} \mathrm{C} 1$ cycle & 150 & 290 & 9.0 & 61.4 & 6.9 & 291 & 6.8 & 41.9 & 32.2 \\
\hline $500{ }^{\circ} \mathrm{C} 5$ cycles & 107 & 165 & 1.6 & 13.1 & 0.56 & 59.9 & 8.0 & 108 & 101 \\
\hline $600^{\circ} \mathrm{C} 5$ cycles & 70.2 & 93.5 & 0.8 & 6.2 & 0.2 & 21.2 & 7.9 & 106 & 120 \\
\hline
\end{tabular}


Table 2. Permeances and Ideal Selectivities of Aged Nano-Hybrid and Control (Un-doped) Carbon Molecular Sieve Membranes.

\begin{tabular}{|c|c|c|c|c|c|c|c|c|c|}
\hline \multirow[b]{2}{*}{ Membrane } & \multicolumn{6}{|c|}{ Permeance [GPU] } & \multicolumn{3}{|c|}{ Ideal Selectivity [-] } \\
\hline & $\mathrm{He}$ & $\mathbf{H}_{2}$ & $\mathbf{N}_{2}$ & $\mathrm{O}_{2}$ & $\mathrm{CH}_{4}$ & $\mathrm{CO}_{2}$ & $\mathrm{O}_{2} / \mathbf{N}_{2}$ & $\mathrm{CO}_{2} / \mathrm{CH}_{4}$ & $\mathrm{H}_{2} / \mathrm{N}_{2}$ \\
\hline $\begin{array}{l}500{ }^{\circ} \mathrm{C} 0 \text { cycle* } \\
\text { (30 days aged) }\end{array}$ & 94.0 & 193.3 & 12.1 & 51.1 & 9.2 & 278.0 & 4.2 & 30.2 & 16.0 \\
\hline $\begin{array}{l}600{ }^{\circ} \mathrm{C} 0 \text { cycle* } \\
(30 \text { days aged })\end{array}$ & 119.0 & 254.3 & 12.6 & 79.1 & 10.9 & 402.7 & 6.3 & 36.9 & 20.1 \\
\hline $\begin{array}{l}500^{\circ} \mathrm{C} 1 \text { cycle } \\
\text { (30 days aged) }\end{array}$ & 57.4 & 95.0 & 2.1 & 12.6 & 1.1 & 76.5 & 6.0 & 69.5 & 45.2 \\
\hline $\begin{array}{l}600{ }^{\circ} \mathrm{C} 1 \text { cycle } \\
\text { (30 days aged) }\end{array}$ & 33.5 & 83.9 & 0.95 & 7.4 & 0.46 & 36.2 & 7.8 & 78.7 & 88.3 \\
\hline $\begin{array}{l}500{ }^{\circ} \mathrm{C} 1 \text { cycle } \\
(60 \text { days aged })\end{array}$ & 39.7 & 66.8 & 0.95 & 6.9 & 0.62 & 38.1 & 7.2 & 62.6 & 69.9 \\
\hline $\begin{array}{l}600{ }^{\circ} \mathrm{C} 1 \text { cycle } \\
\text { (60 days aged) }\end{array}$ & 31.4 & 51.7 & 0.43 & 4.0 & $(-)$ & 16.8 & 9.1 & $>85$ & 118.3 \\
\hline
\end{tabular}

(-) below detection limits; ${ }^{*}$ - data from our earlier study [30]

The physical aging process was tracked up to 60 days for the nano-hybrid CMS membranes prepared using 1 VPI cycle and pyrolyzed at 500 and $600{ }^{\circ} \mathrm{C}$. As mentioned earlier, physical aging presents a considerable challenge especially in thin-film composite membranes where the natural densification of the amorphous glassy structures leads to dramatic loss of permeability [41,42]. Yet, physical aging behavior has very rarely been reported especially in studies dealing with thin-skinned CMS membranes [16]. In our previous work [30], we have established that indeed thin-film CMS membranes tend to rapidly densify with time and that reduction of film thickness had a dramatic effect on the permeability but exerted a rather insignificant influence on the selectivity, Table 2. This was explained by a predominant collapse of the larger micropores in the range roughly $7-20 \AA$ that were principally responsible for the drop in permeability. For $\sim 1$ micron thick unmodified CMS membranes 30 days of aging under ambient conditions resulted in a 3-5 fold reduction of permeability (particularly for higher pyrolysis temperatures $>700{ }^{\circ} \mathrm{C}$ ) with almost no change in selectivity [30]. In this regard, the physical aging behavior of the VPI-derived nano-hybrid CMS membranes appears significantly different. In the case of three of the most technologically important gas pairs, $\mathrm{CO}_{2} / \mathrm{CH}_{4}, \mathrm{O}_{2} / \mathrm{N}_{2}$ and $\mathrm{H}_{2} / \mathrm{N}_{2}$, physical aging led to very large increases in selectivity concurrently with unavoidable reductions of permeances. For example, for the control (un-doped) samples pyrolyzed at 600 ${ }^{\circ} \mathrm{C}, 30$ days of aging resulted in only small or detrimental changes of $\mathrm{O}_{2} / \mathrm{N}_{2}, \mathrm{CO}_{2} / \mathrm{CH}_{4}$ and $\mathrm{H}_{2} / \mathrm{N}_{2}$ selectivities from 7.0 to $6.3,35.3$ to 36.9 , and 28.9 to 20.1 , respectively. On the other hand, hybrid CMS membranes recorded very significant selectivity increases of 6.8 to 7.8, 41.9 to 78.7 , and 32.2 to 88.3 , respectively, for the same aging period. The already high selectivities continued to increase beyond 30 days of aging, Table 2 , accompanied with a commensurate drop in gas permeances. 
Finally, we note that the VPI process itself builds on the extensive experience of the vapor deposition community (in particular, atomic layer deposition ALD) and presents a very wide tunability with: (i) multitude of organo-metallic precursors available (trimethylaluminum, diethyl zinc, titanium tetrachloride etc.), (ii) multiple deposition sequences (continuous, semi-static, pulsed depositions) or (iii) protocols (contacting time of the organo-metallic precursor with the polymer matrix, reaction temperature). In addition, infiltration depths and profiles could be further tuned by pre-treatment of PIM-PI precursors with organic solvents which is known to lead to even more open structures that could, in turn, facilitate metalorganic precursor diffusion. This leads to very attractive optimization possibilities to further fine-tune the separation properties as well as the long-term performance of hybrid, organic-inorganic thin-film composite membranes. These possibilities are not necessarily limited to approaches relying on a subsequent pyrolysis and fabrication of CMS-type membranes. Furthermore, because of its limited invasiveness we further envision a possibility to modify the as-fabricated composite membranes (either flat-sheet or hollow fibers) by exposing them to the organo-metallic precursor and an oxidant after the principal membrane formation step. This would present an attractive membrane modification strategy with a minimal impact on the entire process of membrane fabrication. VPI-derived introduction of specific catalytic functionalities provided by some heavy metal atoms (like Pd) might represent another possibility for novel hybrid membrane properties.

\section{Conclusions}

In this work, we introduced nano-hybrid thin-film composite carbon molecular sieve (CMS) membranes by combining vapor phase infiltration (VPI) with high temperature pyrolytic collapse of an intrinsically microporous organic polymer matrix. While $\mathrm{Al}_{2} \mathrm{O}_{3}$ was used in this study, VPI allows for a molecular level dispersion of a wide range of metal oxides and a high tunability of the process by building on the extensive experience of the vapor deposition community. The synthesized nano-hybrid CMS membranes showed excellent gas separation performance and position themselves near or above state-of-the-art polymeric membranes. VPI enables obtaining very high gas-pair selectivities (e.g. $\left.\mathrm{CO}_{2} / \mathrm{CH}_{4}>100\right)$ typical to hightemperature pyrolized CMS membranes at, however, temperatures lower by $200-300{ }^{\circ} \mathrm{C}$. This may have significant practical applications for the scale up by enabling a much wider spectrum of available CMS supports and alleviating some of the challenges related with very high pyrolysis temperatures such as poor mechanical membrane stability and fabrication complexity.

\section{Acknowledgments}

This work was supported by KAUST baseline funding for I.P. (BAS/1/1323-01-01). W.O. is thankful for an extensive possibility to use KAUST Solar Center facilities for ellipsometry characterization. 


\section{Supporting Information}

Supporting information contains additional data on X-Ray photoelectron spectroscopy, scanning electron microscopy, optical imaging, atomic force microscopy, secondary ion mass spectrometry and spectroscopic ellipsometry analyses.

\section{Data Availability}

The raw and processed data required to reproduce these findings are available to download from https://www.dropbox.com/s/9rcump755cgvuan/VPI\%20ano13\%20SBFDA-DMN_NEW1.opj?dl=0

\section{References}

[1] D.S. Sholl, R.P. Lively, Seven chemical separations to change the world, Nature. 532 (2016) 435-437. doi:10.1038/532435a.

[2] D.F. Sanders, Z.P. Smith, R. Guo, L.M. Robeson, J.E. McGrath, D.R. Paul, B.D. Freeman, Energy-efficient polymeric gas separation membranes for a sustainable future: A review, Polymer 54 (2013) 4729-4761. doi:10.1016/j.polymer.2013.05.075.

[3] Y. Wang, X. Ma, B.S. Ghanem, F. Alghunaimi, I. Pinnau, Y. Han, Polymers of intrinsic microporosity for energyintensive membrane-based gas separations, Mater. Today Nano. 3 (2018) 69-95. doi:10.1016/j.mtnano.2018.11.003.

[4] R.P. Lively, D.S. Sholl, From water to organics in membrane separations: Membrane materials provide economical means to achieve various separation processes - And their capabilities for processing organic fluids look set to expand significantly., Nat. Mater. 16 (2017) 276-279. doi:10.1038/nmat4860.

[5] O. Sanyal, C. Zhang, G.B. Wenz, S. Fu, N. Bhuwania, L. Xu, M. Rungta, W.J. Koros, Next generation membranes using tailored carbon, Carbon 127 (2018) 688-698. doi:10.1016/j.carbon.2017.11.031.

[6] W.J. Koros, C. Zhang, Materials for next-generation molecularly selective synthetic membranes, Nat. Mater. 16 (2017) 289-297. doi:10.1038/nmat4805.

[7] C. Zhang, W.J. Koros, Ultraselective carbon molecular sieve membranes with tailored synergistic sorption selective properties, Adv. Mater. 29 (2017) 1701631. doi:10.1002/adma.201701631.

[8] P.M. Budd, B.S. Ghanem, S. Makhseed, N.B. McKeown, K.J. Msayib, C.E. Tattershall, Polymers of intrinsic microporosity (PIMs): robust, solution-processable, organic nanoporous materials, Chem. Commun. 4 (2004) $230-231$. doi:10.1039/b311764b.

[9] N.B. McKeown, P.M. Budd, Polymers of intrinsic microporosity (PIMs): Organic materials for membrane separations, heterogeneous catalysis and hydrogen storage, Chem. Soc. Rev. 35 (2006) 675-683. doi:10.1039/b600349d.

[10] R.J. Swaidan, X. Ma, I. Pinnau, Spirobisindane-based polyimide as efficient precursor of thermally-rearranged and carbon molecular sieve membranes for enhanced propylene/propane separation, J. Membr. Sci. 520 (2016) 983-989. doi:10.1016/j.memsci.2016.08.057.

[11] O. Salinas, X. Ma, Y. Wang, Y. Han, I. Pinnau, Carbon molecular sieve membrane from a microporous spirobisindanebased polyimide precursor with enhanced ethylene/ethane mixed-gas selectivity, RSC Adv. 7 (2017) 3265-3272. doi:10.1039/c6ra24699k.

[12] H. Hu, X. Fan, Y. He, A coupled thermodynamic model for transport properties of thin films during physical aging, Polymers 11 (2019) 387. doi:10.3390/polym11030387.

[13] Y. Huang, D.R. Paul, Experimental methods for tracking physical aging of thin glassy polymer films by gas permeation, J. Membr. Sci. 244 (2004) 167-178. doi:10.1016/j.memsci.2004.06.058.

[14] B. Frieberg, E. Glynos, P.F. Green, Structural relaxations of thin polymer films, Phys. Rev. Lett. 108 (2012) 268304. doi:10.1103/PhysRevLett.108.268304. 
[15] D. Punsalan, W.J. Koros, Thickness-dependent sorption and effects of physical aging in a polyimide sample, J. Appl. Polym. Sci. 96 (2005) 1115-1121. doi:10.1002/app.21544.

[16] L. Xu, M. Rungta, J. Hessler, W. Qiu, M. Brayden, M. Martinez, G. Barbay, W.J. Koros, Physical aging in carbon molecular sieve membranes, Carbon 80 (2014) 155-166. doi:10.1016/j.carbon.2014.08.051.

[17] Z.X. Low, P.M. Budd, N.B. McKeown, D.A. Patterson, Gas permeation properties, physical aging, and its mitigation in high free volume glassy polymers, Chem. Rev. 118 (2018) 5871-5911. doi:10.1021/acs.chemrev.7b00629.

[18] C.H. Lau, P.T. Nguyen, M.R. Hill, A.W. Thornton, K. Konstas, C.M. Doherty, R.J. Mulder, L. Bourgeois, A.C.Y. Liu, D.J. Sprouster, J.P. Sullivan, T.J. Bastow, A.J. Hill, D.L. Gin, R.D. Noble, Ending aging in super glassy polymer membranes, Angew. Chemie - Int. Ed. 53 (2014) 5322-5326. doi:10.1002/anie.201402234.

[19] M. Alberto, R. Bhavsar, J.M. Luque-Alled, A. Vijayaraghavan, P.M. Budd, P. Gorgojo, Impeded physical aging in PIM1 membranes containing graphene-like fillers, J. Membr. Sci. 563 (2018) 513-520. doi:10.1016/j.memsci.2018.06.026.

[20] M.G. Kamath, S. Fu, A.K. Itta, W. Qiu, G. Liu, R. Swaidan, W.J. Koros, 6FDA-DETDA: DABE polyimide-derived carbon molecular sieve hollow fiber membranes: Circumventing unusual aging phenomena, J. Membr. Sci. 546 (2018) 197-205. doi:10.1016/j.memsci.2017.10.020.

[21] C. Dresbach, G. Hause, T. Brauniger, M. Knez, Y. Qin, U. Gosele, S.-M. Lee, E. Pippel, C. V. Chandran, Greatly Increased Toughness of Infiltrated Spider Silk, Science 324 (2009) 488-492. doi:10.1126/science.1168162.

[22] I. Azpitarte, M. Knez, Vapor phase infiltration: from a bioinspired process to technologic application, a prospective review, MRS Commun. 8 (2018) 727-741. doi:10.1557/mrc.2018.126.

[23] C.Z. Leng, M.D. Losego, Vapor phase infiltration (VPI) for transforming polymers into organic-inorganic hybrid materials: A critical review of current progress and future challenges, Mater. Horizons. 4 (2017) 747-771. doi:10.1039/c7mh00196g.

[24] S. Obuchovsky, H. Frankenstein, J. Vinokur, A.K. Hailey, Y.L. Loo, G.L. Frey, Mechanism of metal oxide deposition from atomic layer deposition inside nonreactive polymer matrices: effects of polymer crystallinity and temperature, Chem. Mater. 28 (2016) 2668-2676. doi:10.1021/acs.chemmater.6b00159.

[25] A. Subramanian, N. Tiwale, C.Y. Nam, Review of recent advances in applications of vapor-phase material infiltration based on atomic layer deposition, Jom. 71 (2019) 185-196. doi:10.1007/s11837-018-3141-4.

[26] H.C. Yang, R.Z. Waldman, Z. Chen, S.B. Darling, Atomic layer deposition for membrane interface engineering, Nanoscale. 10 (2018) 20505-20513. doi:10.1039/c8nr08114j.

[27] E. McGuinness, K., F. Zhang, Y. Ma, R. P. Lively, M. D. Losego, Vapor Phase Infiltration of Metal Oxides into Nanoporous Polymers for Organic Solvent Separation Membranes, Chem. Mater. (2019) in press doi:10.1021/acs.chemmater.9b01141.

[28] S. Greil, A. Rahman, M. Liu, C.T. Black, Gas transport selectivity of ultrathin, nanoporous, inorganic membranes made from block copolymer templates, Chem. Mater. 29 (2017) 9572-9578. doi:10.1021/acs.chemmater.7b04174.

[29] X. Ma, B. Ghanem, O. Salines, E. Litwiller, I. Pinnau, Synthesis and effect of physical aging on gas transport properties of a microporous polyimide derived from a novel spirobifluorene-based dianhydride, ACS Macro Lett. 4 (2015) 231235. doi:10.1021/acsmacrolett.5b00009.

[30] W. Ogieglo, A. Furchner, X. Ma, K. Hazazi, A.T. Alhazmi, I. Pinnau, Thin composite carbon molecular sieve membranes from a polymer of intrinsic microporosity precursor, ACS Appl. Mater. Interfaces. 11 (2019) 18770-18781. doi:10.1021/acsami.9b04602.

[31] W. Ogieglo, H. Wormeester, M. Wessling, N.E. Benes, Spectroscopic ellipsometry analysis of a thin film composite membrane consisting of polysulfone on a porous $\alpha$-alumina support, ACS Appl. Mater. Interfaces. 4 (2012) 935-943. doi:10.1021/am2015958.

[32] W. Ogieglo, H. van der Werf, K. Tempelman, H. Wormeester, M. Wessling, A. Nijmeijer, N.E. Benes, N-Hexane induced swelling of thin PDMS films under non-equilibrium nanofiltration permeation conditions, resolved by spectroscopic ellipsometry, J. Membr. Sci. 431 (2013) 313-323. doi:10.1016/j.memsci.2012.12.045.

[33] B. Johs, J.S. Hale, Dielectric function representation by B-splines, Phys. Status Solidi Appl. Mater. Sci. 205 (2008) $715-$ 719. doi:10.1002/pssa.200777754. 
[34] D.A.G. Bruggeman, Berechnung verschiedener physikalischer Konstanten von heterogenen Substanzen. I. Dielektrizitätskonstanten und Leitfähigkeiten der Mischkörper aus isotropen Substanzen, Ann. Phys. 416 (1935) 636664. doi:10.1002/andp.19354160705.

[35] T. Lichtenstein, Handbook of thin film materials, College of Engineering and Applied Science, University of Rochester, 1979.

[36] G.N. Parsons, S.E. Atanasov, E.C. Dandley, C.K. Devine, B. Gong, J.S. Jur, K. Lee, C.J. Oldham, Q. Peng, J.C. Spagnola, P.S. Williams, Mechanisms and reactions during atomic layer deposition on polymers, Coord. Chem. Rev. 257 (2013) 3323-3331. doi:10.1016/j.ccr.2013.07.001.

[37] Y. Sun, R.P. Padbury, H.I. Akyildiz, M.P. Goertz, J.A. Palmer, J.S. Jur, Influence of subsurface hybrid material growth on the mechanical properties of atomic layer deposited thin films on polymers, Chem. Vap. Depos. 19 (2013) $134-141$. doi:10.1002/cvde.201207042.

[38] C.Z. Leng, M.D. Losego, A physiochemical processing kinetics model for the vapor phase infiltration of polymers: Measuring the energetics of precursor-polymer sorption, diffusion, and reaction, Phys. Chem. Chem. Phys. 20 (2018) 21506-21514. doi:10.1039/c8cp04135k.

[39] J.G. Wijmans, R.W. Baker, The solution-diffusion model: a review, J. Membr. Sci. 107 (1995) 1-21. doi:10.1016/03767388(95)00102-I.

[40] K. Hazazi, X. Ma, Y. Wang, W. Ogieglo, A. Alhazmi, Y. Han, I. Pinnau, Ultra-selective carbon molecular sieve membranes for natural gas separations based on a carbon-rich intrinsically microporous polyimide precursor, J. Membr. Sci. 585 (2019) 1-9. doi:10.1016/j.memsci.2019.05.020.

[41] Y. Huang, D.R. Paul, Physical aging of thin glassy polymer films monitored by gas permeability, Polymer 45 (2004) 8377-8393. doi:10.1016/j.polymer.2004.10.019.

[42] Y. Huang, D.R. Paul, Effect of temperature on physical aging of thin glassy polymer films, Macromolecules. 38 (2005) 10148-10154. doi:10.1021/ma051284g. 


\section{Vitae}

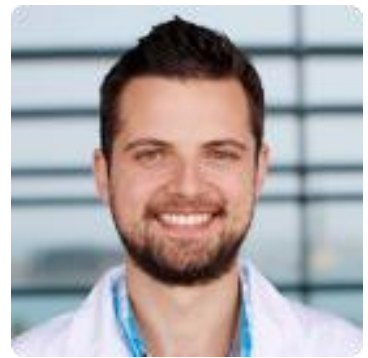

Wojciech Ogieglo is Research Scientist at King Abdullah University of Science and Technology in Kingdom of Saudi Arabia. He received his PhD degree (cum laude) from the University of Twente in the Netherlands in 2014 followed by two postdoctoral fellowships at the University of Twente and DWI Leibniz Institute for Interactive Materials in Germany. He has co-authored 40 peer-reviewed articles in the field of chemical engineering, physics of thin polymer films, and membrane science and technology. His current research activities deal with thin and ultra-thin composite membranes comprising amorphous microporous materials, such as polymers of intrinsic microporosity and carbon molecular sieves.

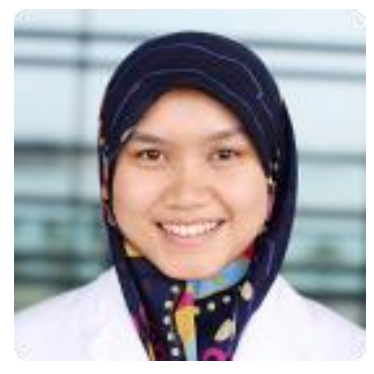

Tiara Puspasari currently works as a postdoctoral fellow at the Advanced Membranes and Porous Materials Center, King Abdullah University of Science and Technology (KAUST). She received her PhD in the same university in 2018. Her research lies in the area of membrane development and characterization, thin film composites from bio- and synthetic polymers, and various membrane applications including nanofiltration, gas and vapor separations.

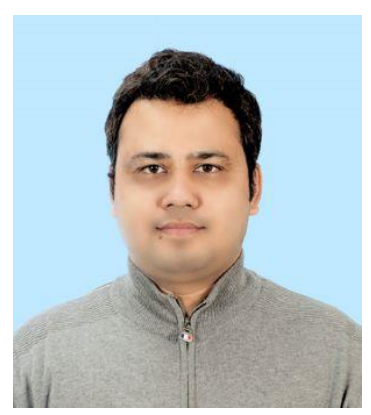

Mrinal Kanti Hota received his Ph.D. degree in Engineering from Jadavpur University, Kolkata, India, in May 2013. He is currently working as a Research Scientist at King Abdullah University of Science and Technology (KAUST), Saudi Arabia. His current research interests include transparent oxide thin films, thin film transistor, resistive switching memory devices, and electrochemical transistors.

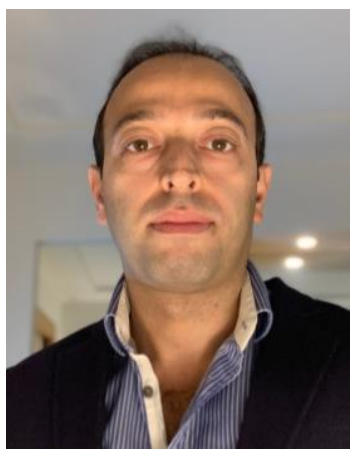

Nimer Wehbe is a Senior Scientist in the Imaging and Characterization Core Lab at King Abdullah University of Science and Technology (KAUST). He received his $\mathrm{PhD}$ degree (2006) in Physics from the University of Lyon in France where he was involved in fundamental studies dealing with material characterization using ion beams. He worked for more than nine years as researcher at several Universities and research centers in Europe. Through his professional career evidenced by numerous published papers and conference talks, he has built a strong background in the field of material characterization using various surface analysis techniques such as SIMS and XPS. 


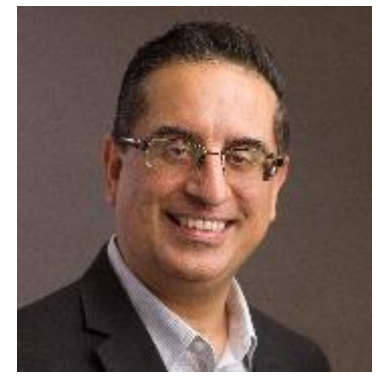

Husam Alshareef is a Processor of Materials Science and Engineering at King Abdullah University of Science and Technology (KAUST). He obtained his PhD at NC State University in 1996 followed by a post-doctoral Fellowship at Sandia National Laboratory, USA. He then embarked on a 10-year career in the semiconductor industry, holding positions at Micron Technology and Texas Instruments. There he worked on developing new materials and processes for the microelectronics industry. In 2009 he joined KAUST, where he initiated an active research group focusing on energy storage and electronics. The author of nearly 375 articles, he has nearly 70 issued patents. He has won the UNDP Undergraduate Fellowship, Seth Sprague Physics Award, NC State Dean's Fellowship, U.S. Department of Education Electronic Materials Fellowship, the SEMATECH Corporate Excellence Award (2006), two Dow Sustainability Awards (2011) and (2014), AH Shoman Award for Excellence in Energy Research (2016), and KAUST Distinguished Teaching Award (2018), and the Kuwait Prize for Sustainable and Clean Technologies (2018). He is a fellow of the Royal Society of Chemistry and IEEE Distinguished Speaker in Nanotechnology. He was co-chair for the 2014 Materials Research Society (MRS) Fall Meeting in Boston.

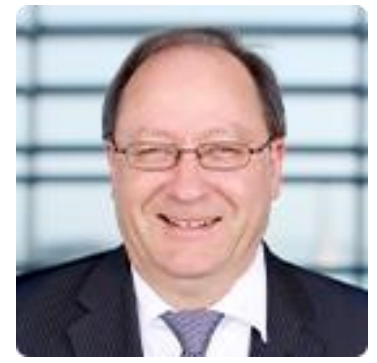

Ingo Pinnau is Professor of Chemical Engineering and served as Founding Director of the Advanced Membranes and Porous Materials at King Abdullah University of Science and Technology from 2009-2017. Dr. Pinnau received his Ph.D. in Chemical Engineering from the University of Texas at Austin in 1991 and worked for 18 years as Director of Materials and Membrane Development at Membrane Technology and Research, Inc., Menlo Park, CA. He has been a consulting Professor at Stanford University. Dr. Pinnau co-edited four books on membrane science and is the author of $170+$ publications and more than 300 presentations. He holds 45 U.S. patents and was Board member and two-term President of the North American Membrane Society (NAMS). He chaired the NAMS National Meeting in 2004 and the International Conference on Membranes and Membrane Processes (ICOM) in 2008. He is on the editorial board of the Journal of Membrane Science and Applied Water Science. Dr. Pinnau holds various professional memberships and has received several national and international awards. 